by the Mattingly ${ }^{11}$ technique, followed by administration of lysine vasopressin by intramuscular injection ${ }^{5}$ or intravenous infusion $^{9}$ and serial estimations of the plasma cortisol. The maximum value usually occurs after one hour, when control levels exceed $23.6 \mu \mathrm{g}$. per $100 \mathrm{ml}$. of plasma. ${ }^{5}$ Side-effects have been slight, including pallor, increased intestinal mobility, and uterine contractions. It would seem wise to avoid the test in patients with clinical evidence of ischaemic heart disease, since vasopressin may constrict coronary vessels. ${ }^{12}$ No changes in blood-pressure have been recorded. ${ }^{5}$

Further studies are required to localize the precise site of action of lysine vasopressin in man. The evidence suggests that it acts by releasing pituitary corticotrophin and not by direct stimulation of the adrenal cortex. Whether it does so or not, it should be useful in the investigation of pituitary and hypothalamic disorders, since it appears to act by mechanisms independent of those operated in existing tests.

\section{Transmission of Disease by Blood Transfusion}

Hepatitis, ${ }^{1}$ syphilis, malaria, and brucellosis have all been transmitted to patients who were given whole blood or blood products. Hepatitis is by far the most serious disorder transmitted in this way, and the incidence of the disease in patients receiving an average of two bottles of blood is about $0.8 \%$. When plasma from relatively large pools is used the incidence can reach the alarming figure of $11.9 \%$, but if the plasma pool is prepared from less than 10 bottles the figure falls to $1.3 \%$. After a massive blood transfusion-and between 10 and 20 bottles is commonplace in modern heart surgery-the risk is once again increased. This important hazard of blood transfusion is not as widely appreciated as it should be: one of the reasons for this may be the relatively long incubation period, which varies from 60 to 160 days before jaundice appears.

The signs and symptoms are better known. In addition to jaundice, about two thirds of patients have nausea, vomiting, and anorexia, joint pains are present in about a quarter and a skin rash may develop. The illness lasts about 30 days. Seven out of 134 cases reported by $D$. Lehane and his colleagues ${ }^{2}$ died. The work of G. S. Mirick, R. Ward, and R. W. McCollum ${ }^{3}$ suggested that giving gamma-globulin may reduce the frequency of hepatitis after transfusion, and there is much to be said for adopting this form of prophylaxis with large transfusions.

Where malaria is endemic the transmission by transfusion remains a hazard. N. N. Duhanina and T. A. Zukova ${ }^{4}$ report 47 cases, including the transmission of quartan malaria to children who were given maternal blood as prophylaxis against measles. Another 36 cases are recorded from Yugoslavia." Transmission of malaria by transfusion can be prevented by the administration of chloroquine diphosphate to the recipient before the transfusion. A dose of $600 \mathrm{mg}$. seems to be adequate. ${ }^{6}$

1 Brit. med. F., 1966, 1.997.

Lehane, D., Kwantes, C. M. S., Upward, M. G., and Thomson, D. R., Brit. med. f., 1949, 2, 572.

- Mirick, G. S., Ward, R., and McCollum, R. W.. Vox Sang., 1962, 7, 125.

- Duhanina, N. N., and Zukova, T. A., Bull. Wld Hlth Org., 1965, 33, 853.

5 Lepeš, T., ibid., 1965, 33, 856.

Tiburskaja, N. A., and Vrublevskaja, O. S., ibid., 1965, 33, 843.

7 Bloch, O., Bull. Fohns Hopk. Hosp., 1941, 68, 412.

- Wood, E. E., Brit. med. F., 1955, 1, 27.
Transmission of syphilis is less likely because spirochaetes are unlikely to survive for more than 72 hours in stored citrated blood, ${ }^{\top}$ and transmission of brucellosis, though reported, ${ }^{8}$ must be a rarity.

Most transfusion services do not accept as donors those who give a history of jaundice. Nevertheless, cven after this step is taken the known incidence of homologous serum jaundice suggests that not less than 1 in 200 healthy donors are carriers of the virus. Whole blood from donors who have lived in areas where malaria is endemic should not be transfused, though there is no objection to the use of their plasma. It is also the practice to carry out serological tests for syphilis on donor blood samples and to exclude donors giving positive reactions.

\section{Karachi Meeting}

At page 107 of this week's Supplement is printed the programme of the Joint Annual Meeting of the B.M.A. and the Pakistan Medical Association, to be held in Karachi from 19 November to 3 December. The President-Elect, Professor Hamid Ali Khan, and his committee have produced a varied scientific programme and have drawn speakers from Africa, Asia, and Britain. Certainly no one who has read the programme need seek any further justification for leaving the British winter for the warmth and hospitality of Pakistan. Delegates to the meeting will also have the chance of attending some other medical meetings in Asia and the Far East. The World Medical Association is holding its twentieth General Assembly in Manila from 6 to 12 November, and has arranged the Third World Conference on Medical Education, which will take place in New Delhi from 20 to 25 November. Other congresses taking place in October and November include the Fifth World Conference of Cardiology in New Delhi and the Ninth International Cancer Congress in Tokio.

Registration forms are now available for the Karachi Meeting and may be obtained from the Secretary, Joint Annual Meeting, Karachi, 1966, B.M.A. House, Tavistock Square, London W.C.1. A tour has been arranged in connexion with the Meeting at an inclusive cost of $£ 30210$ s. Details are given in the Supplement.

The scientific sessions at Karachi strike a good balance between refresher teaching and new knowledge. The symposia will deal with conditions which will be of interest to doctors from all parts of the world, and the speakers will discuss the practical aspects of a range of common problems such as obesity, abdominal emergencies, and antenatal care. Some shorter sessions on the theme of "What's New" will present up-to-date information in fields such as the abnormal haemoglobins, where knowledge is advancing rapidly. The plenary session on "Planned Parenthood" has, perhaps, particular relevance for Asia and should provide a stimulating opening.

The social programme at Annual Meetings is always an added attraction for delegates, and many who will be visiting Pakistan for the first time will welcome the opportunity to see something of the country. Two evenings of music and dancing will give visitors an impression of the cultural heritage of Pakistan. Doctors from Pakistan have already made many friends for their country while working in Britain. The joint meeting gives British doctors the opportunity to strengthen the ties between the two countries. 